\title{
Prevalence of Hyperuricemia and the Relationship Between Serum Uric Acid Concentrations and Lipid Parameters Among King Abdulaziz University Hospital Patients
}

\section{Ranya A. Ghamri}

King Abdulaziz University Hospital

Tala A. Qalai ( $\square$ tala.qalai@gmail.com )

King Abdulaziz University Faculty of Medicine https://orcid.org/0000-0002-4942-5590

Raghad A. Ismail

King Abdulaziz University Faculty of Medicine

Joud M. Aljehani

King Abdulaziz University Faculty of Medicine

Dina S. Alotaibi

King Abdulaziz University Faculty of Medicine

Maysam A. Aljahdali

King Abdulaziz University Faculty of Medicine

\section{Research}

Keywords: serum uric acid, lipid profile, hyperuricemia

Posted Date: March 15th, 2021

DOI: https://doi.org/10.21203/rs.3.rs-306744/v1

License: (c) (1) This work is licensed under a Creative Commons Attribution 4.0 International License.

Read Full License 


\section{Abstract}

Background: Hyperuricemia is a metabolic defect caused by high purine consumption, overproduction of uric acid, or reduced uric acid excretion. Hyperuricemia is the second most common metabolic disease after diabetes mellitus and can mediate proinflammatory endocrine imbalance in adipose tissue, which contributed to dyslipidemia. Furthermore, several studies have associated uric acid with dyslipidemia. However, no previous studies have examined patients without chronic illness. Thus, we aimed to assess the relationship between serum uric acid concentration and lipid profile parameters and to estimate the prevalence of hyperuricemia in the city of Jeddah.

Methods: A retrospective study was conducted among 1206 patients without chronic illness after applying the exclusion criteria. Patients had undergone laboratory blood testing over a 3-year period (2018-2020) at King Abdulaziz University Hospital, which was ethically approved. We used a predesigned checklist to collect data from electronic hospital records using Google Forms. Bivariate analysis, tables, and graphs were used to represent and identify the relationships between variables. A Pvalue of $<0.05$ was considered significant.

Results: Our study revealed a prevalence of $12 \%$ for hyperuricemia in the study population. Males were more frequently affected than females $(8.13 \%$ vs. $3.73 \%$, respectively). There was no association between serum uric acid concentration and lipid profile parameters, including total cholesterol $(P=0.92)$, triglyceride $(P=0.42)$, high-density lipoprotein $(P=0.47)$, and low-density lipoprotein $(P=0.66)$. There was a strong association between serum uric acid concentration and high body mass index $(P<0.001)$, older age $(P=0.002)$, male sex $(P<0.001)$, and nationality $(P<0.001)$. Furthermore, there was an association between sex and mean erythrocyte sedimentation rate $(P=0.02)$ and mean triglyceride concentration $(P=0.02)$.

Conclusion: We observed a low prevalence of hyperuricemia, and our results indicate no association between serum uric acid concentration and lipid profile parameters.

\section{Background}

The ultimate product of human purine metabolism is uric acid (UA) (1). Around two-thirds of serum UA is produced endogenously, and one-third comes from exogenous dietary purines (2). Approximately $70 \%$ of serum UA is excreted by the kidneys, and the remainder is excreted by the intestine (2). However, metabolic defects, an increase in purine consumption or production, and a decrease in excretion can cause abnormal accumulation of UA in the blood, leading to hyperuricemia. Hyperuricemia is defined as an increase in blood urate concentration of $>420 \mu \mathrm{mol} / \mathrm{L}(7.0 \mathrm{mg} / \mathrm{dL})(3,4)$.

The prevalence of hyperuricemia is increasing rapidly, not only in developed countries $(5,6)$, but also in low- and middle-income countries $(7,8)$. It has become the second most common metabolic disorder after diabetes mellitus (9). The prevalence of hyperuricemia is $21.4 \%$ in the US (6), $18.6 \%$ in Bangladesh (10), $11.4 \%$ in Korea (11), 6.4\% in China (12), and $8.4 \%$ in Saudi Arabia (13). 
Serum UA concentration is affected by age, sex, environment, dietary intake, and other factors (9). Many epidemiological studies reported a close association between hyperuricemia and gout, metabolic syndrome, obesity, diabetes mellitus, and cardiovascular disease $(14,15)$. However, the exact roles of UA in these diseases is not clear due to its association with other risk factors, such as lifestyle and dyslipidemia (16).

Hyperuricemia can mediate proinflammatory endocrine imbalances in adipose tissue, which contribute to dyslipidemia (17). The lipid profile test measures four basic parameters: total cholesterol (TC), highdensity lipoprotein (HDL), low-density lipoprotein (LDL), and triglycerides (TG). A previous study showed a strong association between serum UA concentration and LDL, TG, TC, and HDL (18). Furthermore, hyperuricemia is related to an increase in blood TG concentration, independent of metabolic syndrome (19). Similarly, a study conducted in Al-Kharj, Saudi Arabia, found a strong association between UA and TG (20).

A cross-sectional study of 3093 subjects aged 18-85 years in China revealed that high TG and TC concentrations were positively associated with hyperuricemia in males, but not in females (21). However, results from another study among 9,580 subjects aged $>45$ years showed that high TG and TC concentrations are strongly associated with hyperuricemia in males, but only a high TG concentration is strongly associated with hyperuricemia in females (22).

A careful literature review revealed that studies assessing the association between serum UA and lipid profiles among patients without chronic illness in Saudi Arabia, especially in Jeddah, are lacking. The present study is designed to identify the relationship between serum UA and lipid profiles and to estimate the prevalence of hyperuricemia among Saudi adult patients at King Abdulaziz University Hospital from 2018 to 2020.

\section{Methods}

\section{Study setting and design}

This study was conducted at King Abdulaziz University Hospital, which is a tertiary care center in Jeddah on the Western Coast of Saudi Arabia. The study adopted a retrospective design.

\section{Sampling methodology}

A total of 1206 patients were included in the study during a 3-year period from January 2018 to July 2020. The inclusion criteria were adult patients who underwent blood sampling for laboratory testing and absence of severe illness. The exclusion criteria were pregnancy and lactation, myeloproliferative disorders, therapy with cytotoxic drugs, diuretic or anti-hypertensive drug use, alcoholism, cardiovascular disease, renal or hepatic disorders, and anti-gout therapy. Patients with incomplete data regarding UA or lipid profiles were excluded. The number of patients with missing data for erythrocyte sedimentation rate (ESR), C-reactive protein (CRP), vitamin D, and white blood cell (WBC) counts was 746, 821, 974, and 28, 
respectively, either because these parameters were not routinely ordered with serum UA and lipid profile tests or had not been updated in patient files.

\section{Study instruments}

A predesigned checklist was prepared to collect data using Google Forms. Data was then transferred to Google Sheets. The first section included items designed to collect data on demographic characteristics, height, weight, and comorbidities. The second section included items to collect the results of laboratory blood analyses, including serum UA concentration $(\mu \mathrm{mol} / \mathrm{L}), \mathrm{TG}$ concentration $(\mathrm{mmol} / \mathrm{L}), \mathrm{TC}$ concentration (mmol/L), HDL concentration ( $\mathrm{mmol} / \mathrm{L})$, LDL concentration ( $\mathrm{mmol} / \mathrm{L})$, very-LDL (VLDL) concentration $(\mathrm{mmol} / \mathrm{L})$, ESR $(\mathrm{mm} / \mathrm{h})$, CRP concentration $(\mathrm{mg} / \mathrm{L})$, vitamin D concentration $(\mathrm{nmol} / \mathrm{L})$, and WBC count $(\mathrm{k} / \mu \mathrm{L})$.

According to our hospital laboratory, patients were categorized as having hyperuricemia if the serum UA concentration was $>428 \mu \mathrm{mol} / \mathrm{L}(23,24)$. Additional classification was performed for serum UA concentrations by dividing into four quartiles as follows: Q1 = serum UA $\leq 225 \mu \mathrm{mol} / \mathrm{L}, \mathrm{Q} 2=$ serum UA $226-285 \mu \mathrm{mol} / \mathrm{L}, \mathrm{Q} 3=$ serum UA $286-340 \mu \mathrm{mol} / \mathrm{L}, \mathrm{Q} 4=$ serum $U A>340 \mu \mathrm{mol} / \mathrm{L}(10)$. Optimal concentrations of TC, TG, HDL, and $\mathrm{LDL}$, and ESR, CRP concentration, vitamin D concentration, and WBC count were 0-5.20 mmol/L, 0.30-2.30 mmol/L, 0.9-1.55 mmol/L, 0-3.57 mmol/L, 1-20 mm/h, 0-3 $\mathrm{mg} / \mathrm{L}, 75-250 \mathrm{nmol} / \mathrm{L}$, and $4.5-11.5 \mathrm{k} / \mu \mathrm{L}$, respectively $(23,25)$. Patients were considered as underweight if $B M I$ was $<18.5 \mathrm{~kg} / \mathrm{m}^{2}$, normal if BMI was $18.5-24.99 \mathrm{~kg} / \mathrm{m}^{2}$, overweight if $\mathrm{BMI}$ was $25-29.99 \mathrm{~kg} / \mathrm{m}^{2}$, and obese if $\mathrm{BMI}$ was $\geq 30 \mathrm{~kg} / \mathrm{m}^{2}(26)$.

\section{Ethical considerations}

The study was approved by the research ethics committee of the Faculty of Medicine of King Abdulaziz University Hospital. Data were stored at the principle investigator's office and were only accessed by the authors (Reference No: 646-19).

\section{Statistical analysis}

Data were coded, tabulated, and analyzed using SPSS version 20 (IBM Corp., Armonk, NY, USA).

Qualitative data are expressed as numbers and percentages, and the Chi-squared test $\left(\chi^{2}\right)$ was used to test the relationship between variables. Quantitative data are expressed as mean \pm standard deviation, and the Mann-Whitney Utest and Kruskal-Wallis test were used to analyze non-parametric variables. A correlation analysis was performed using Spearman's correlation. A P-value of $<0.05$ was considered statistically significant.

\section{Results}

This study evaluated the link between serum UA and lipid profiles and the prevalence of hyperuricemia among adult patients at King Abdulaziz University Hospital in Jeddah, Saudi Arabia, during a 3-year 
period from 2018 to 2020 . A total of 1206 patients were enrolled in our study, with a mean age of $44.3 \pm$ 14.2 years and a mean BMl of $23.4 \pm 7.6 \mathrm{~kg} / \mathrm{m}^{2}$. Females constituted the majority of the sample $(62.9 \%)$, while only $37.1 \%$ of patients were male.

The sample distribution among demographic characteristics, BMI categories, and lipid profile parameters is summarized in Table 1. The mean lipid profile parameters were as follows: TC: $4.76 \pm 1.28 \mathrm{mmol} / \mathrm{L}$; TG: $1.62 \pm 1.06 \mathrm{mmol} / \mathrm{L} ; \mathrm{HDL}: 1.3 \pm 0.42 \mathrm{mmol} / \mathrm{L} ; \mathrm{LDL}: 3.09 \pm 1.01 \mathrm{mmol} / \mathrm{L}$. Other laboratory measures were as follows: WBC count: $7.8 \pm 8.0 \mathrm{k} / \mu \mathrm{L}$; ESR: $23.1 \pm 22.4 \mathrm{~mm} / \mathrm{h}$; CRP: $18.12 \pm 33.8 \mathrm{mg} / \mathrm{L}$; vitamin D: 49.68 $\pm 70.4 \mathrm{nmol} / \mathrm{L}$. 
Table 1

Distribution of patients according to their characteristics, demographics, BMI categories, and lipid profile parameters.

\begin{tabular}{|ll|}
\hline Variable & No (\%) \\
\hline Gender & \\
Female & $447(37.1)$ \\
\hline Nationality & $759(62.9)$ \\
Non-Saudi & \\
Saudi & $461(38.2)$ \\
\hline BMI categories $\left(\mathrm{kg} / \mathrm{m}^{2}\right)$ & $747(61.8)$ \\
Underweight & $190(16)$ \\
Normal weight & $610(51.3)$ \\
Overweight & $283(23.8)$ \\
Obese & $106(8.9)$ \\
\hline TG categories $(\mathrm{mmol} / \mathrm{L})$ & \\
High & $227(18.8)$ \\
Low & $2(0.2)$ \\
Normal & $977(81)$ \\
\hline TC categories $(\mathrm{mmol} / \mathrm{L})$ & \\
High & $426(35.3)$ \\
Normal & $780(64.7)$ \\
\hline HDL categories $(\mathrm{mmol} / \mathrm{L})$ & \\
High & $287(23.8)$ \\
Low & $156(12.9)$ \\
Normal & $763(63.6)$ \\
\hline LDL categories $(\mathrm{mmol} / \mathrm{L})$ & \\
\hline Normal & \\
\hline
\end{tabular}

BMI, body mass index; TG, triglyceride; TC, total cholesterol; LDL, low-density lipoprotein; HDL, highdensity lipoprotein. 
To determine the prevalence of hyperuricemia, patients were divided according to their serum UA concentration into high, low, and normal groups, with a mean serum UA concentration of $298.27 \pm 104.2$ $\mu \mathrm{mol} / \mathrm{L}$. A serum UA concentration of $>428 \mu \mathrm{mol} / \mathrm{L}$ was considered as hyperuricemia and was observed in 134 patients $(11.9 \%)$. A total of $47(3.9 \%)$ and $1016(84.2 \%)$ patients had low and normal serum UA concentrations, respectively (Fig. 1).

With regard to the relationship between serum UA concentration and other factors, sex, nationality, and BMI had a significant relationship with mean serum UA concentration $(P<0.001)$. However, only a weak positive correlation was observed between serum UA concentration and age and BMI $(P<0.001)$. Table 2 shows the results of a bivariate analysis, and Table 3 shows relative risk and correlation data in addition to other numerical variables. 
Table 2

Bivariate analysis between mean serum UA concentration and patients.

\begin{tabular}{|c|c|c|}
\hline Variable & $\begin{array}{l}\text { Serum UA } \\
\text { (mean } \pm \text { SD) }\end{array}$ & P-value \\
\hline Gender & & $<0.001$ \\
\hline Male & $353.24 \pm 102.41$ & \\
\hline Female & $266.61 \pm 91.19$ & \\
\hline Nationality & & $<0.001$ \\
\hline Non-Saudi & $317.48 \pm 114.41$ & \\
\hline Saudi & $287.11 \pm 95.66$ & \\
\hline BMI categories $\left(\mathrm{kg} / \mathrm{m}^{2}\right)$ & & $<0.001$ \\
\hline Underweight & $266.99 \pm 94.59$ & \\
\hline Normal weight & $292.85 \pm 101.93$ & \\
\hline Overweight & $322.49 \pm 108.64$ & \\
\hline Obese & $331.04 \pm 88.76$ & \\
\hline TG categories (mmol/L) & & 0.42 \\
\hline High & $306.62 \pm 111.32$ & \\
\hline Low & $258.50 \pm 3.53$ & \\
\hline Normal & $296.96 \pm 102.58$ & \\
\hline TC categories (mmol/L) & & 0.92 \\
\hline High & $298.27 \pm 103.05$ & \\
\hline Normal & $298.96 \pm 104.94$ & \\
\hline HDL categories $(\mathrm{mmol} / \mathrm{L})$ & & 0.47 \\
\hline high & $292.98 \pm 102.71$ & \\
\hline low & $305.92 \pm 108.45$ & \\
\hline normal & $299.40 \pm 103.95$ & \\
\hline LDL categories (mmol/L) & & 0.66 \\
\hline High & $298.06 \pm 107.65$ & \\
\hline Normal & $299.01 \pm 102.74$ & \\
\hline
\end{tabular}


BMI, body mass index; TG, triglyceride; TC, total cholesterol; LDL, low-density lipoprotein; HDL, highdensity lipoprotein.

Table 3

Correlation analysis and relative risk between serum UA concentration and numerical variables.

\begin{tabular}{|lll|}
\hline Variable & \multicolumn{2}{l|}{ Serum UA } \\
\cline { 2 - 3 } & $\mathbf{r}$ & P-value \\
\hline Age & 0.16 & $<0.001$ \\
\hline BMI $\left(\mathrm{kg} / \mathrm{m}^{2}\right)$ & 0.22 & $<0.001$ \\
\hline TG $(\mathrm{mmol} / \mathrm{L})$ & 0.03 & 0.22 \\
\hline TC $(\mathrm{mmol} / \mathrm{L})$ & 0.03 & 0.27 \\
\hline $\mathrm{HDL}(\mathrm{mmol} / \mathrm{L})$ & 0.03 & 0.19 \\
\hline $\mathrm{LDL}(\mathrm{mmol} / \mathrm{L})$ & 0.007 & 0.81 \\
\hline ESR $(\mathrm{mm} / \mathrm{h})$ & 0.04 & 0.35 \\
\hline CRP $(\mathrm{mg} / \mathrm{L})$ & 0.006 & 0.91 \\
\hline Vitamin D $(\mathrm{nmol} / \mathrm{L})$ & 0.01 & 0.56 \\
\hline WBC $(\mathrm{k} / \mu \mathrm{L})$ & 0.04 & 0.15 \\
\hline
\end{tabular}

BMI, body mass index; TG, triglyceride; TC, total cholesterol; LDL, low-density lipoprotein; HDL, highdensity lipoprotein; ESR, erythrocyte sedimentation rate; CRP, C-reactive protein; WBC, white blood cell.

Scatter plots of UA concentration against BMI, serum UA concentration against age, and BMI against age are shown in Fig. 2. Figure 3 shows that patients classed as overweight and obese had a significantly higher serum UA concentration $(P \leq 0.05)$. A higher mean serum UA concentration was more frequently observed in males, non-Saudi patients, and patients classified as obese. Although there were high serum UA concentrations in patients with high TG and low HDL concentrations, and low serum UA concentrations in patients with normal and high LDL concentrations, a non-significant relationship was observed between mean serum UA concentration and participants' lipid profiles $(P>0.05)$. Table 4 shows that regardless of normal or abnormal serum UA concentrations, the serum UA quartiles showed the same significant relationship with age, sex, nationality, and BMI. Older patients, males, non-Saudi patients, and patients classified as overweight formed the highest percentage of patients with high serum UA concentrations $(P<0.001)$. We used binary logistic regression (Table 5$)$ to identify independent predictors of abnormal serum UA concentration. The male sex, non-Saudi nationality, and high BMI were independent predictors of an abnormal serum UA concentration. 
Page 10/22 
Table 4

Distribution of patients among the serum UA quartiles and bivariate analysis between serum UA quartiles and related factors.

\begin{tabular}{|c|c|c|c|c|c|}
\hline \multirow[t]{4}{*}{ Variable } & \multicolumn{4}{|c|}{ Serum UA quartile } & \multirow[t]{4}{*}{ P-value } \\
\hline & Q1 & Q2 & Q3 & Q4 & \\
\hline & $\leq 225$ & $226-285$ & $286-340$ & $>340$ & \\
\hline & No (\%) & No (\%) & No (\%) & No (\%) & \\
\hline Age, years (mean \pm SD) & $\begin{array}{l}40.55 \pm \\
12.84\end{array}$ & $44.4 \pm 13.85$ & $45.9 \pm 14.83$ & $46.62 \pm 14.65$ & $<0.001$ \\
\hline Gender & & & & & $<0.001$ \\
\hline Male & $31(6.9)$ & $82(18.3)$ & $103(23)$ & $231(51.7)$ & \\
\hline Female & $275(36.2)$ & $229(30.2)$ & $131(17.3)$ & 124 (16.3) & \\
\hline Nationality & & & & & 0.001 \\
\hline Non-Saudi & $92(20)$ & $118(25.6)$ & $88(19.1)$ & $163(35.4)$ & \\
\hline Saudi & $214(28.7)$ & $123(25.9)$ & $146(19.6)$ & $192(25.8)$ & \\
\hline BMI $\left(\mathrm{kg} / \mathrm{m}^{2}\right)$ & & & & & $<0.001$ \\
\hline Underweight & $76(40)$ & $46(24.2)$ & $30(15.8)$ & $38(20)$ & $<0.001$ \\
\hline Normal weight & $166(27.2)$ & 163 (26.7) & 118 (19.3) & $163(26.7)$ & \\
\hline Overweight & $44(15.5)$ & $73(25.7)$ & $65(23)$ & 101 (35.7) & \\
\hline Obese & $13(12.3)$ & $22(20.8)$ & $21(19.7)$ & $50(47.2)$ & \\
\hline $\mathrm{BMI}($ mean $\pm \mathrm{SD})$ & $21.73 \pm 8.1$ & $23.2 \pm 8.55$ & $23.98 \pm 5.69$ & $24.74 \pm 7.38$ & \\
\hline TG (mmol/L) & & & & & 0.15 \\
\hline High & $57(25.1)$ & $51(22.2)$ & $41(18.1)$ & 78 (34.4) & 0.1 \\
\hline Low & $0(0.0)$ & $2(100)$ & $0(0.0)$ & $0(0.0)$ & \\
\hline Normal & 249 (25.5) & 258 (26.4) & 193 (19.8) & 277 (28.4) & \\
\hline TG $($ mean \pm SD $)$ & $1.67 \pm 0.91$ & $1.56 \pm 1.15$ & $1.63 \pm 1.08$ & $1.64 \pm 1.1$ & \\
\hline TC (mmol/L) & & & & & 0.67 \\
\hline High & 108 (25.4) & 112 (26.3) & 75 (17.6) & $131(30.8)$ & 0.2 \\
\hline Normal & 198 (25.4) & 199 (25.5) & 159 (20.4) & $224(28.7)$ & \\
\hline $\mathrm{TC}($ mean $\pm \mathrm{SD})$ & $4.77 \pm 1.2$ & $4.86 \pm 1.29$ & $4.61 \pm 1.25$ & $4.75 \pm 1.34$ & \\
\hline
\end{tabular}




\begin{tabular}{|c|c|c|c|c|c|}
\hline \multirow[t]{4}{*}{ Variable } & \multicolumn{4}{|c|}{ Serum UA quartile } & \multirow[t]{4}{*}{ P-value } \\
\hline & Q1 & Q2 & Q3 & Q4 & \\
\hline & $\leq 225$ & $226-285$ & $286-340$ & $>340$ & \\
\hline & No (\%) & No (\%) & No (\%) & No (\%) & \\
\hline \multicolumn{5}{|l|}{ HDL (mmol/L) } & 0.91 \\
\hline High & $77(26.8)$ & $75(26.1)$ & $54(18.8)$ & $81(28.2)$ & \multirow[t]{4}{*}{0.67} \\
\hline Low & $41(26.3)$ & 37 (23.7) & 27 (17.3) & $51(32.7$ & \\
\hline Normal & $188(24.6)$ & $199(26.1)$ & $153(20.1)$ & $223(29.2)$ & \\
\hline $\mathrm{HDL}($ mean $\pm \mathrm{SD})$ & $1.23 \pm 0.42$ & $1.3 \pm 0.45$ & $1.29 \pm 0.4$ & $1.28 \pm 0.41$ & \\
\hline \multicolumn{6}{|l|}{ LDL (mmol/L) } \\
\hline High & $97(26.1)$ & $98(26.4)$ & $79(21.3)$ & $97(26.1)$ & 0.36 \\
\hline Normal & $209(25)$ & $213(25.5)$ & $155(18.6)$ & $258(30.9)$ & \multirow[t]{2}{*}{0.25} \\
\hline $\mathrm{LDL}($ mean $\pm \mathrm{SD})$ & $3.08 \pm 1.04$ & $3.12 \pm 1.04$ & $3.18 \pm 1.01$ & $3.02 \pm 0.79$ & \\
\hline \multirow{5}{*}{$\begin{array}{l}\operatorname{ESR}(\mathrm{mm} / \mathrm{h}) \\
\operatorname{CRP}(\mathrm{mg} / \mathrm{L}) \\
\operatorname{Vitamin} \mathrm{D}(\mathrm{nmol} / \mathrm{L}) \\
\text { WBC }(\mathrm{k} / \mu \mathrm{L})\end{array}$} & \multirow[t]{2}{*}{$\begin{array}{l}23.87 \pm \\
19.72\end{array}$} & \multirow[t]{2}{*}{$\begin{array}{l}21.18 \pm \\
22.86\end{array}$} & \multirow[t]{2}{*}{$\begin{array}{l}24.14 \pm \\
23.29\end{array}$} & $23.55 \pm 23.82$ & 0.39 \\
\hline & & & & $24.94 \pm 45.99$ & 0.3 \\
\hline & $\begin{array}{l}13.58 \pm \\
18.92\end{array}$ & $\begin{array}{l}20.84 \pm \\
38.35\end{array}$ & $\begin{array}{l}10.44 \pm \\
14.55\end{array}$ & $\begin{array}{l}57.39 \pm \\
123.05\end{array}$ & 0.57 \\
\hline & $\begin{array}{l}48.07 \pm \\
32.08\end{array}$ & $\begin{array}{l}46.77 \pm \\
27.14\end{array}$ & \multirow{2}{*}{$7.35 \pm 3.58$} & \multirow[t]{2}{*}{$7.75 \pm 5.11$} & \multirow{2}{*}{0.13} \\
\hline & $8.54 \pm 14.37$ & $7.46 \pm 2.7$ & & & \\
\hline
\end{tabular}

BMI, body mass index; TG, triglyceride; TC, total cholesterol; LDL, low-density lipoprotein; HDL, highdensity lipoprotein; ESR, erythrocyte sedimentation rate; CRP, C-reactive protein; WBC, white blood cell.

Table 5

Binary logistic regression analysis to identify independent predictors of abnormal serum uric acid concentration.

\begin{tabular}{|lllll|}
\hline Variable & \multicolumn{2}{l}{ Serum UA } & \multicolumn{2}{c|}{ P-value } \\
\cline { 2 - 4 } & Beta & Wald & $\operatorname{Exp~(B)~}$ & \\
\hline Gender & 0.94 & 34.06 & 2.57 & $<0.001$ \\
\hline Nationality & 0.59 & 13.34 & 1.82 & $<0.001$ \\
\hline BMI & 0.02 & 6.1 & 0.97 & 0.01 \\
\hline
\end{tabular}

UA, uric acid. 


\section{Discussion}

This study aimed to assess the prevalence of hyperuricemia and the relationship between serum UA concentration and lipid profile parameters in Saudi Arabia. Among the 1206 participants, the prevalence of hyperuricemia at King Abdulaziz University Hospital was $12 \%$. Males were more frequently affected than females ( $8.13 \%$ vs. $3.73 \%$, respectively), which is in agreement with previous studies. The prevalence of hyperuricemia is $21.4 \%$ in the USA (6), $18.6 \%$ in Bangladesh (10), $11.4 \%$ in Korea (11), and $6.4 \%$ in China (12). The most likely reasons for variation in the prevalence of hyperuricemia between our study and other studies are cultural differences and differences in eating habits. Saudi Arabia's cuisine generally includes meat, which is a rich source of UA. Also, populations on the Western Coast often consume seafood. Villegas et al. stated that animal protein and seafood consumption are associated with a high prevalence of hyperuricemia (27). In a cross-sectional study conducted in China, a high intake of fresh meat and fish were quadrated with a high prevalence of hyperuricemia (28). Moreover, a prospective study performed in Riyadh, the capital of Saudi Arabia, showed that high consumption of meat-based foods in the central region of Saudi Arabia is a risk factor for hyperuricemia. Thus, there is strong evidence that hyperuricemia is highly associated with food intake (13).

Our findings reveal that the majority of participants with high serum UA concentrations had high TC and TG concentrations, a low HDL concentration, and a normal LDL concentration. However, there was no significant association between UA concentration and lipid profile parameters. Li et al. claimed no association between serum UA concentration and lipid profile parameters, and an elevated serum UA concentration was identified as a dyslipidemia-independent risk factor for hyperuricemia. Moreover, a high UA concentration significantly affects anti-oxidant reduction rate, whereas UA concentration does not interfere with hyperlipidemia-associated factors (29). Alaqi et al. conducted a study among the adult population of Al-Kharj to assess the association between UA concentration and lipid profile. The study included patients taking anti-hypertensive and anti-diabetic medications in addition to healthy individuals. They found a significant association between serum UA concentration and TG concentration, but no association was observed between UA concentration and TC concentration. However, there was no significant difference between serum UA, TC, or TG concentrations in patients who were taking antihypertensive medications compared with those who were not. The study showed a significant difference in TG concentrations among patients using anti-diabetic medications (30). Another study conducted in Al-Kharj found no significant association between serum UA concentration and TG, TC, and HDL concentrations (31). In addition, a study conducted in Sudan on 219 participants, $25 \%$ of whom had metabolic syndrome and $24.7 \%$ of whom were hypertensive, revealed no significant relationship between serum UA concentration and LDL and HDL concentrations. However, there was a significant relationship between serum UA concentration and TG and TC concentrations (32). In terms of the determinants of blood UA concentration in Arabic patients with dyslipidemia, a study conducted in Kuwait showed a significant relationship between serum UA concentration and TG concentration; however, there was no significant association between UA concentration and TC, LDL, and HDL concentrations (33). In contrast, Cibickova et al. conducted a cross-sectional study that supported the association between serum UA concentration and lipid profile (18). These differences in the association between serum UA concentration 
and lipid profile parameters may have been influenced by comorbidities and medications. In our study, participants were considered as free from chronic illness; thus, comorbidities and concomitant medications would not have been an influencing factor.

We observed a relationship between serum UA concentration and high BMI, old age, male sex, and nationality, which corroborates other studies. In a cross-sectional study conducted in Japan, serum UA concentration was strongly associated with $\mathrm{BMI}$, and a decrease in $\mathrm{BMI}$ contributed to an improvement in serum UA concentration (34). Ismail et al. revealed that a high UA concentration was significantly associated with BMI (32), which supports our result. Furthermore, Zhang et al. stated that hyperuricemia is associated with age and sex (35). Another study showed that UA concentration is strongly related to the male sex (36). This phenomenon is related to the sex hormone estrogen, and the protective effect of estrogen has been addressed in a previous study (37). Estrogen promotes UA excretion by decreasing the tubular reabsorption of urate. Therefore, the age-associated decline in estrogen in females is accompanied by an increase in serum UA. Additionally, aging can result in low physical activity, which leads to visceral fat accumulation, obesity, and insulin resistance. Consequently, urinary excretion of UA is reduced (38). Also, we suggest that high UA concentrations are more frequently observed in males than females because males have a greater muscle mass, which is reflected as a high BMI, whereas the opposite is true for females.

We also observed a significant relationship between serum UA concentration and the Saudi nationality. Specifically, non-Saudis had a higher mean serum UA concentration and a higher prevalence of hyperuricemia compared with Saudis. This outcome is somewhat unexpected, considering that the majority of participants were of Saudi nationality (61.8\%). This variation might be due to differences in genetic factors, lifestyle, and eating habits, particularly cultural food traditions, which are highlighted in the Saudi Arabian Society and may contribute to high UA concentrations as described earlier. According to a study conducted in the USA, the non-Hispanic male population demonstrated high UA concentrations (39). In addition, a review of several genetic studies found that hyperuricemia is common in AfricanAmerican and European populations (40). A study performed in Taiwan found that UA concentrations in Aboriginals were higher compared with non-Aboriginals (41). A population-based study conducted to evaluate the contribution of diet to UA concentration (42) showed that diet accounts for minor variation in UA concentration in contrast to genetics. However, we divided participants in the present study into Saudi and non-Saudi nationalities, and there might be genetic similarities among participants of different nationalities.

In our study, we found no association between serum UA concentration and four factors: ESR, CRP concentration, WBC count, and vitamin D concentration. Liang et al. stated that there is no association between serum UA concentration and ESR (43). Moreover, a study conducted in China demonstrated no association between serum UA concentration and CRP concentration or WBC count (44). Furthermore, an Australian study reported no association between serum UA concentration and vitamin D concentration (45). In contrast, a study performed in Al-Kharj discovered that elevated UA leads to vitamin D deficiency (31); however, UA concentrations in our study were not as high as UA concentrations in their study. We 
hypothesize that vitamin D deficiency is associated with a significantly high UA concentration, which is not reflected in our findings. We suggest that an elevated UA concentration could elevate WBC counts, inflammatory markers, ESR, and CRP concentration. However, the participants in our study had not reached the concentration of UA that would induce inflammatory markers and elevate WBC counts. This may be due to missing data from electronic health records, as these parameters are not routinely measured with serum UA and lipid profile tests.

Furthermore, an association was observed between sex and mean ESR and mean TG concentration. Males had a higher mean ESR compared with females, while females had a higher mean TG concentration compared with males. Siemens et al. showed that ESR was higher in females compared with males (46). We believe genetic variations and use of different measurements to determine ESR may explain this adverse result. Due to the coronavirus disease 2019 crisis, access to the hospital and hospital healthcare system was restricted. In addition, our study focused on a healthy population; thus, we excluded a large number of patients with comorbidities, which may have affected our findings. Finally, incomplete documentation of patients' data and inclusion of cases in which not all lipid profile parameters were requested may have influenced the results.

\section{Conclusion}

The present study aimed to measure the association between serum UA concentration and lipid profile and to determine the prevalence of hyperuricemia in patients at King Abdulaziz University Hospital in Jeddah, Saudi Arabia. In conclusion, the prevalence of hyperuricemia was $12 \%$ in this population and was more common in males compared with females. There was no significant association between serum UA concentration and lipid profile. Serum UA concentration was affected by sex, age, and BMI. Thus, we advise monitoring of serum UA concentrations among older patients and patients with obesity. Further prospective studies on patients with gout and dyslipidemia compared with healthy individuals should be performed. Future studies should also investigate the association between serum UA concentration and other biochemical markers, such as vitamin D, ESR, and CRP.

\section{Abbreviations}

BMI, body mass index

CRP, C-reactive protein

ESR, erythrocyte sedimentation rate

$H D L$, high-density lipoprotein

LDL, low-density lipoprotein

TC, total cholesterol 
TG, triglyceride

UA, uric acid

WBC, white blood cell

\section{Declarations}

Ethics approval and consent to participate: The research was authorized by the institutional review board of King Abdulaziz University Hospital (Reference No: 646-19).

Consent for publication: Not applicable.

Availability of data and materials: All data were handled confidentially and stored at the principle investigator's office. Data were only accessed by the authors. Data are available upon request by contacting the corresponding author.

Competing interests: All authors declare no conflict of interest.

Funding: The study was self-funded.

Authors' contributions: R.G conceptualized and designed the study, analyzed data, and wrote the manuscript. T. Q., R.I., J.A., M.A., and D.O. participated in data collection and analysis and wrote the manuscript. R.G. and T.Q. Decisively reviewed the results and the manuscript. All authors approved the final version of the manuscript.

Acknowledgments: We would like to acknowledge Dr. Mohammed Komou for his guidance in our research project, Abdulkarim Jawhari and Afrah Al Otaibi for their encouragement and advice, and Maha Alghamdi for her help in data collection.

\section{References}

1. Glantzounis G, Tsimoyiannis E, Kappas A, Galaris D. Uric acid and oxidative stress. Curr Pharm Des. 2005;11:4145-51.

2. Schlesinger N. Dietary factors and hyperuricaemia. Curr Pharm Des. 2005;11:4133-8.

3. Dincer HE, Dincer AP, Levinson DJ. Asymptomatic hyperuricemia: to treat or not to treat. Cleve Clin J Med. 2002;69:594-608.

4. Liu F, Du GL, Song N, Ma YT, Li XM, Gao XM, et al. Hyperuricemia and its association with adiposity and dyslipidemia in Northwest China: results from cardiovascular risk survey in Xinjiang (CRS 20082012). Lipids Health Dis. 2020;19:1-12.

5. Kanwar G, Kabra R. Serum uric acid level and obesity: an association. Int J Healthc. 2016;4:52-5. 
6. Zhu Y, Pandya BJ, Choi HK. Prevalence of gout and hyperuricemia in the US general population: the National Health and Nutrition Examination Survey 2007-2008. Arthritis Rheum. 2011;63:3136-41.

7. Chen LY, Zhu WH, Chen ZW, Dai HL, Ren JJ, Chen JH, et al. Relationship between hyperuricemia and metabolic syndrome. J Zhejiang Univ Sci B. 2007;8:593.

8. Conen D, Wietlisbach V, Bovet P, Shamlaye C, Riesen W, Paccaud F, et al. Prevalence of hyperuricemia and relation of serum uric acid with cardiovascular risk factors in a developing country. BMC Public Health. 2004;4:9.

9. Multidisciplinary Expert Task Force on Hyperuricemia and Related Diseases. Chinese multidisciplinary expert consensus on the diagnosis and treatment of hyperuricemia and related diseases. Chin Med J. 2017;130:2473.

10. Ali N, Perveen R, Rahman S, Mahmood S, Rahman S, Islam S, et al. Prevalence of hyperuricemia and the relationship between serum uric acid and obesity: a study on Bangladeshi adults. PLoS One. 2018. doi:10.1371/journal.pone.0206850.

11. Kim Y, Kang J, Kim GT. Prevalence of hyperuricemia and its associated factors in the general Korean population: an analysis of a population-based nationally representative sample. Clin Rheumatol. 2018;37:2529-38.

12. Song P, Wang H, Xia W, Chang X, Wang M, An L. Prevalence and correlates of hyperuricemia in the middle-aged and older adults in China. Sci Rep. 2018;8:1-9.

13. Al-Arfaj AS. Hyperuricemia in Saudi Arabia. Rheumatol Int. 2001;20:61-4.

14. Benn CL, Dua P, Gurrell R, Loudon P, Pike A, Storer RI, et al. Physiology of hyperuricemia and uratelowering treatments. Front Med. 2018;5:160.

15. Ndrepepa G. Uric acid and cardiovascular disease. Clin Chim Acta. 2018;484:150-63.

16. Sarmah D, Sharma B. A correlative study of uric acid with lipid profile. Asian J Med Sci. 2013;4:8-14.

17. Baldwin W, McRae S, Marek G, Wymer D, Pannu V, Baylis C, et al. Hyperuricemia as a mediator of the proinflammatory endocrine imbalance in the adipose tissue in a murine model of the metabolic syndrome. Diabetes. 2011;60:1258-69.

18. Cibičková L, Langová K, Vaverková H, Kubíčková V, Karásek D. Correlation of uric acid levels and parameters of metabolic syndrome. Physiol Res. 2017;66:481.

19. Peng TC, Wang CC, Kao TW, Chan JYH, Yang YH, Chang YW, et al. Relationship between hyperuricemia and lipid profiles in US adults. Biomed Res Int. 2015. doi:10.1155/2015/127596.

20. Ahmed RHA, Mariod AA, El Sanousi SM. Effect of Gum Arabic on the Fecal Bacterial Mass in Healthy Human Volunteers. In: Mariod AA, editor. Gum Arabic: Structure, Properties, Application and Economics. London: Academic; 2018. pp. 297-304.

21. Zhang X, Meng Q, Feng J, Liao H, Shi R, Shi D, et al. The prevalence of hyperuricemia and its correlates in Ganzi Tibetan Autonomous Prefecture, Sichuan Province, China. Lipids Health Dis. 2018;17:235. 
22. Xu J, Peng H, Ma Q, Zhou X, Xu W, Huang L, et al. Associations of non-high density lipoprotein cholesterol and traditional blood lipid profiles with hyperuricemia among middle-aged and elderly Chinese people: a community-based cross-sectional study. Lipids Health Dis. 2014;13:117.

23. Sui X, Church TS, Meriwether RA, Lobelo F, Blair SN. Uric acid and the development of metabolic syndrome in women and men. Metabolism. 2008;57:845-52.

24. You L, Liu A, Wuyun G, Wu H, Wang P. Prevalence of hyperuricemia and the relationship between serum uric acid and metabolic syndrome in the Asian Mongolian area. J Atheroscler Thromb. 2014;21:355-65.

25. Brewer HB Jr. New features of the national cholesterol education program adult treatment panel III lipid-lowering guidelines. Clin Cardiol. 2003;26:19-24.

26. Alberti KGMM, Zimmet P, Shaw J. Metabolic syndrome-a new world-wide definition. A consensus statement from the international diabetes federation. Diabet Med. 2006;23:469-80.

27. Villegas $R$, Xiang YB, Elasy $T, X u$ WH, Cai $H$, Cai Q, et al. Purine-rich foods, protein intake, and the prevalence of hyperuricemia: the Shanghai Men's Health Study. Nutr Metab Cardiovasc Dis. 2012;22:409-16.

28. Liu X, Huang S, Xu W, Zhou A, Li H, Zhang R, et al. Association of dietary patterns and hyperuricemia: a cross-sectional study of the Yi ethnic group in China. Food Nutr Res. 2018. doi:10.29219/fnr.v62.1380.

29. Li L, Song Q, Yang X. Lack of associations between elevated serum uric acid and components of metabolic syndrome such as hypertension, dyslipidemia, and T2DM in overweight and obese Chinese adults. J Diabet Res. 2019. doi:10.1155/2019/3175418.

30. Pathania D, Alaql AB, Almousa Al, Alonazi FS, Aldossari MA. Association between uric acid levels and lipid profiles in adult population of Alkharj city. Egypt J Hosp Med. 2018;71:3648-54.

31. Mohamed GA, Al-Harizi WM, Bedewi MA, Gafar HH. Vitamin D deficiency in knee osteoarthritis and its relationship with obesity in Saudi Arabia. Life Sci J. 2015;12.

32. Elamin MIM. Curriculum vitae (assistant professor at Almughtaribeen University-Faculty of Medicine). 2020.

33. Al-Meshaweh AF, Jafar Y, Asem M, Akanji AO. Determinants of blood uric acid levels in a dyslipidemic Arab population. Med Princ Pract. 2012;21:209-16.

34. Tanaka K, Ogata S, Tanaka H, Omura K, Honda C, Hayakawa K, et al. The relationship between body mass index and uric acid: a study on Japanese adult twins. Environ Health Prev Med. 2015;20:34753.

35. Zhang L, Wan Q, Zhou Y, Xu J, Yan C, Ma Y, et al. Age-related and gender-stratified differences in the association between high triglyceride and risk of hyperuricemia. Lipids Health Dis. 2019;18:147.

36. Lurbe E, Torro MI, Alvarez-Pitti J, Redon J, Borghi C, Redon P. Uric acid is linked to cardiometabolic risk factors in overweight and obese youths. J Hypertens. 2018;36:1840-6. 
37. Sumino H, Ichikawa S, Kanda T, Nakamura T, Sakamaki T. Reduction of serum uric acid by hormone replacement therapy in postmenopausal women with hyperuricaemia. Lancet. 1999;354:650.

38. Facchini F, Chen YDI, Hollenbeck CB, Reaven GM. Relationship between resistance to insulinmediated glucose uptake, urinary uric acid clearance, and plasma uric acid concentration. JAMA. 1991;266:3008-11.

39. DeBoer MD, Dong L, Gurka MJ. Racial/ethnic and sex differences in the relationship between uric acid and metabolic syndrome in adolescents: an analysis of National Health and Nutrition Survey 1999-2006. Metabolism. 2012;61:554-61.

40. Singh JA. Racial and gender disparities among patients with gout. Curr Rheumatol Rep. 2013;15:307.

41. Lai LH, Chou SY, Wu FY, Chen JJH, Kuo HW. Renal dysfunction and hyperuricemia with low blood lead levels and ethnicity in community-based study. Sci Total Environ. 2008;401:39-43.

42. Major TJ, Topless RK, Dalbeth N, Merriman TR. Evaluation of the diet wide contribution to serum urate levels: meta-analysis of population based cohorts. BMJ. 2018;363:k3951.

43. Liang J, Jiang Y, Huang Y, Song W, Li X, Huang Y, et al. The comparison of dyslipidemia and serum uric acid in patients with gout and asymptomatic hyperuricemia: a cross-sectional study. Lipids Health Dis. 2020;19:1-7.

44. Luo M, Li ZZ, Li YY, Chen LZ, Yan SP, Chen P, et al. Relationship between red cell distribution width and serum uric acid in patients with untreated essential hypertension. Sci Rep. 2014;4:1-5.

45. Nabipour I, Sambrook PN, Blyth FM, Janu MR, Waite LM, Naganathan V, et al. Serum uric acid is associated with bone health in older men: a cross-sectional population-based study. J Bone Miner Res. 2011;26:955-64.

46. Siemons L, ten Klooster PM, Vonkeman HE, van Riel PL, Glas CA, van de Laar MA. How age and sex affect the erythrocyte sedimentation rate and C-reactive protein in early rheumatoid arthritis. BMC Musculoskelet Disord. 2014;15:368.

\section{Figures}




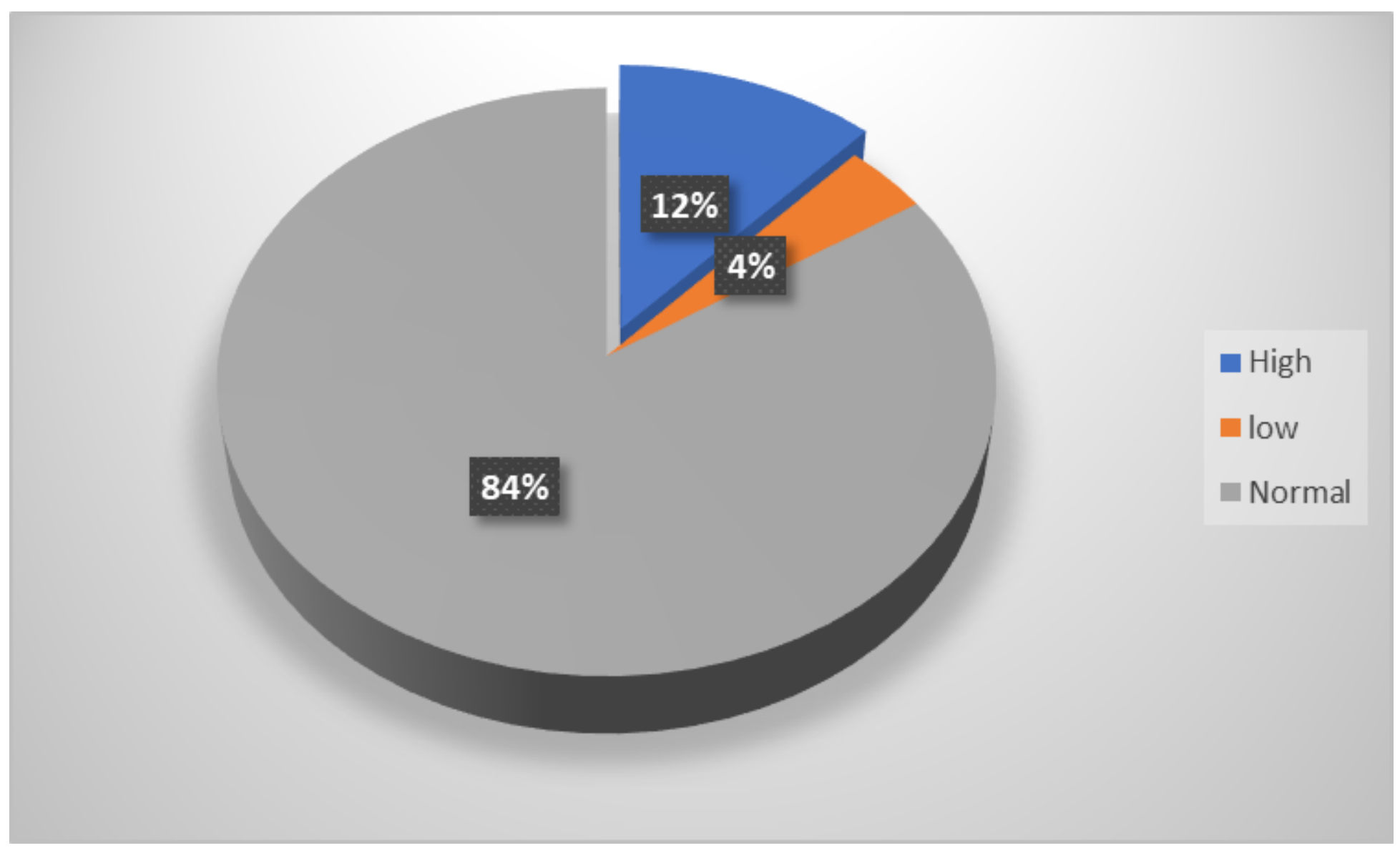

Figure 1

Distribution of studied participants according to serum UA levels. UA, uric acid. 


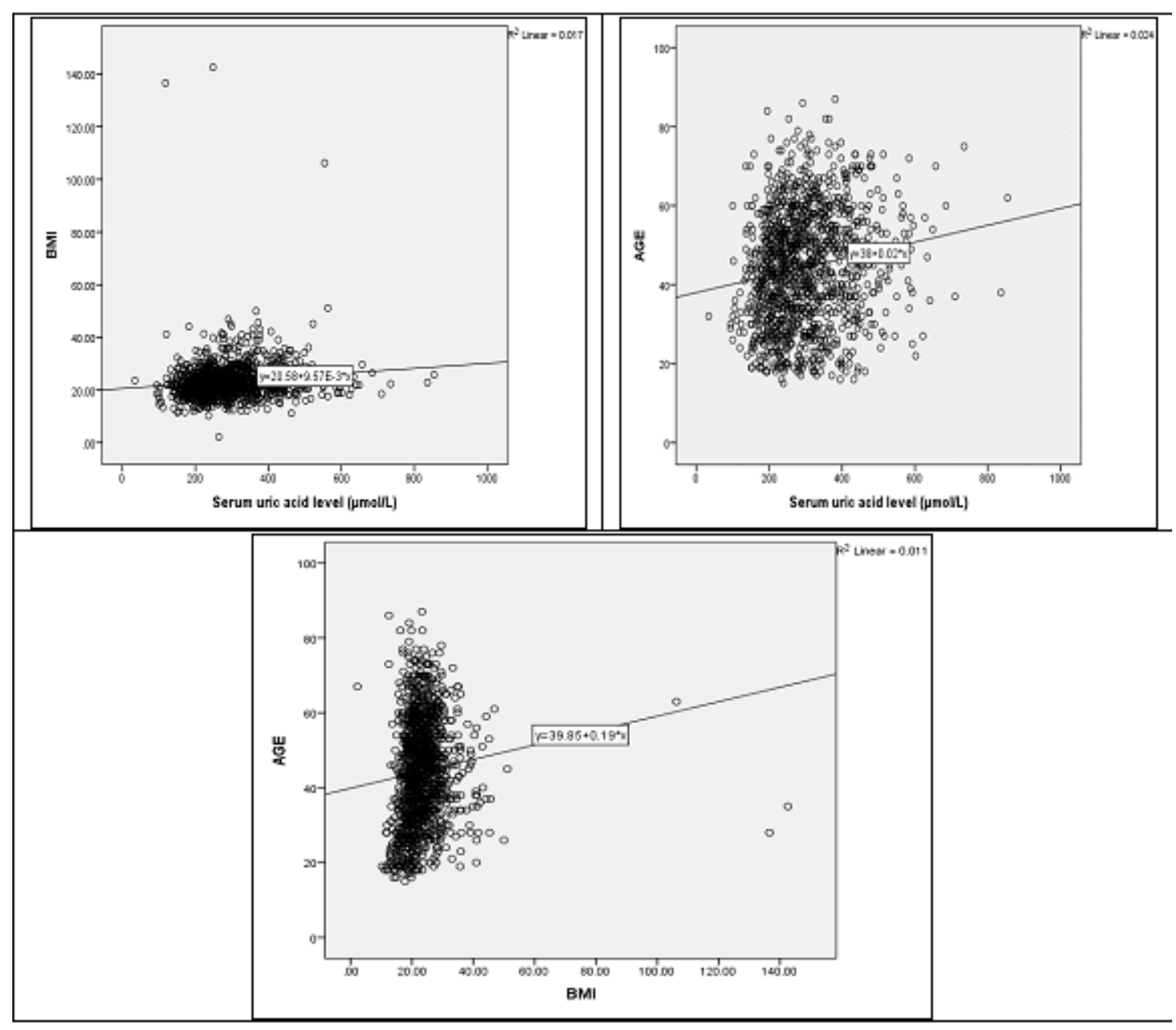

Figure 2

Scatter plots of serum UA against BMI, serum UA against age, and BMI against age. BMI, body mass index. 


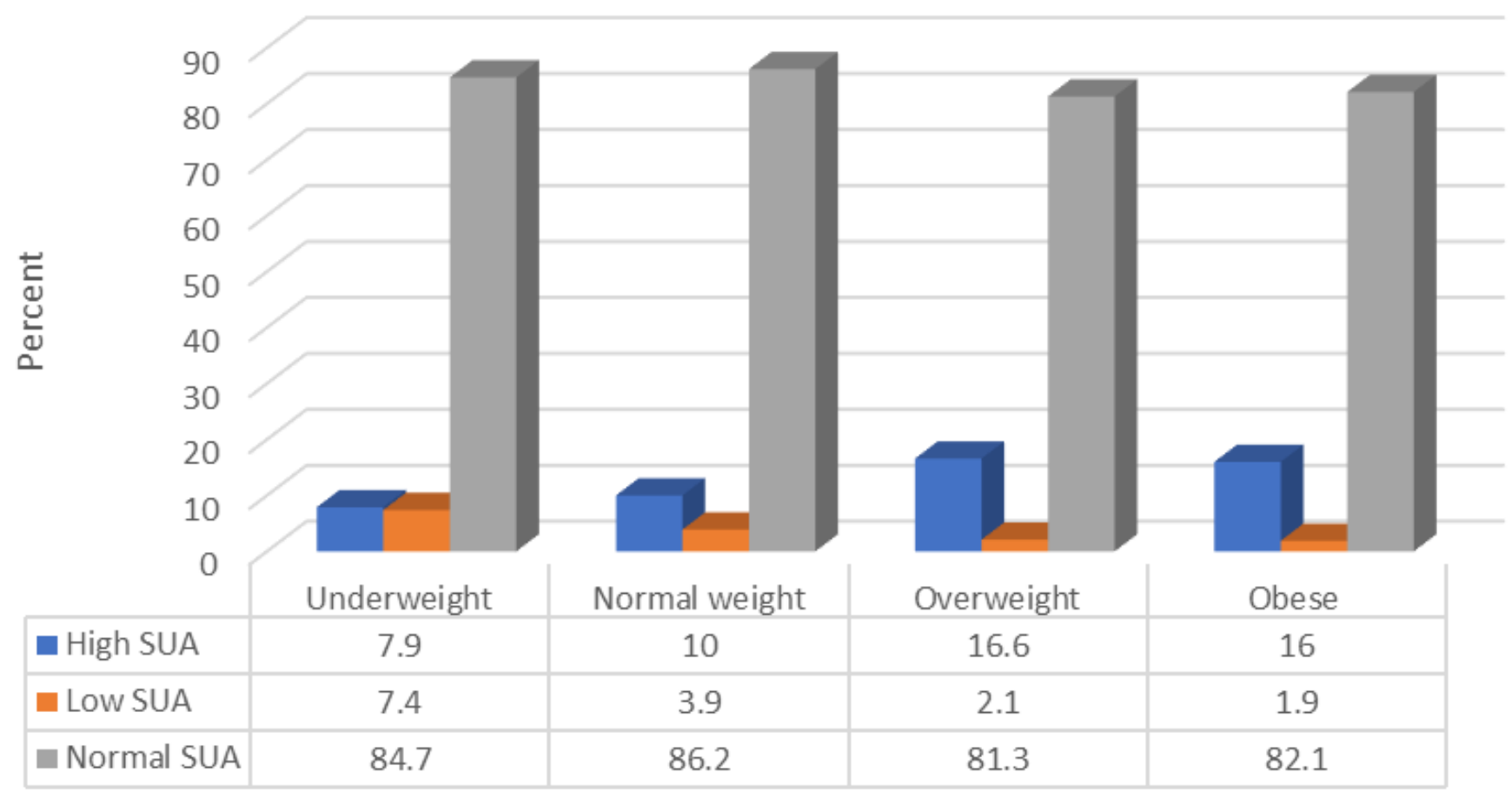

Figure 3

Relationship between serum UA concentration and BMI categories. (S)UA, (serum) uric acid; BMI, body mass index. NB: $\chi 2=21.47 ;$ P-value $=0.002$. 